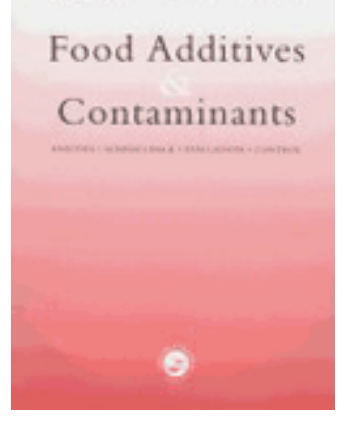

\title{
SORPTION OF AROMA COMPOUNDS IN PET AND PVC DURING THE STORAGE OF A STRAWBERRY SYRUP
}

\begin{tabular}{|r|l|}
\hline Journal: & Food Additives and Contaminants \\
\hline Manuscript ID: & TFAC-2006-253.R1 \\
\hline Manuscript Type: & Original Research Paper \\
\hline Author: & O4-Mar-2007 \\
\hline Complete List of Authors: & $\begin{array}{l}\text { DUCRUET, VIOLETTE; INRA, UMR SCALE } \\
\text { Vitrac, Olivier; INRA, UMR GENIAL } \\
\text { SAILLARD, Philippe; INRA, LNSA } \\
\text { GUICHARD, Elisabeth; INRA, UMR FLAVIC } \\
\text { FEIGENBAUM, Alexandre; INRA, UMR FARE } \\
\text { FOURNIER, Nicole; INRA, UMR FLAVIC }\end{array}$ \\
\hline Methods/Techniques: & Chromatography - GC/MS, Extraction \\
\hline Additives/Contaminants: & Flavourings, Packaging - PET, PET \\
\hline Food Types: & Beverages \\
\hline & \\
\hline
\end{tabular}

\section{SCHOLARONE ${ }^{m}$ Manuscripts}




\section{Sorption of aroma compounds in PET and PVC during the storage of a strawberry syrup}

Violette DUCRUET ${ }^{a^{*}}$, Olivier VITRAC ${ }^{b}$, Philippe SAILLARD ${ }^{c}$, Elisabeth GUICHARD ${ }^{d}$, Alexandre FEIGENBAUM ${ }^{\mathrm{d}}$, and Nicole FOURNIER ${ }^{\mathrm{d}}$

a INRA, Unité Mixte de Recherche SCALE, 1 avenue des Olympiades 91744 Massy CEDEX France. Phone 331699350 47. Fax 33169935020 . Email: violette.ducruet@ agroparistech.fr

b INRA Unité Mixte de Recherche GENIAL, 1 avenue des Olympiades 91744 Massy CEDEX

c: INRA Laboratoire de Nutrition et Sécurité Alimentaire, 78352 Jouy en Josas CEDEX, France

d: INRA, Unité Mixte de Recherche FLAVIC, 17 rue Sully, BV 86510, 21065 Dijon CEDEX, France

e: INRA, Unité Mixte de Recherche FARE, Moulin de la Housse, 51687 Reims, France

* Corresponding author.

Keywords: aroma, PET, PVC, packaging, sorption, strawberry, syrup 


\begin{abstract}
The sorption of 14 aroma compounds into PET and PVC was monitored during storage of a strawberry syrup for 1 year. Concentrations in the syrup and in the polymer were determined during storage and compared with previously published results obtained with glass bottles. Apparent partition coefficients between the polymer and the syrup (noted $\mathrm{K}_{\mathrm{app}}$ ) were estimated from experimental kinetics without reaching equilibrium $\mathrm{K}_{\text {app }}$ values were optimally identified from the kinetic data obtained between 30 and 90 days. They exhibited a similar behaviour for both polymers with values were between $2 \cdot 10^{-5}$ and $2 \cdot 10^{-3}, 4 \cdot 10^{-5}$ and $3 \cdot 10^{-2}$ respectively for PET and PVC. The variation of $\mathrm{K}_{\mathrm{app}}$ values in PET was mainly correlated to the polarity of tested compounds as assessed by their $\log \mathrm{P}$ values. By contrast, the variations in $\mathrm{K}_{\mathrm{app}}$ values for PVC were mainly related to their chain lengths. Due to slightly higher partition coefficients and diffusion coefficients in PVC compared to PET, the amount of absorbed aroma was 4 times higher in PVC than in PET, however the amount of absorbed aroma compounds was less than $0.1 \%$ of the initial amount present into the syrup, except for octyl butanoate.. The variation in concentration in the syrup was interpreted as a combination of a degradation process and a transport process into the packaging material. Both effects were particularly noticeable for both PET and unstable aroma compounds.
\end{abstract}




\section{Introduction}

The absorption of aroma compounds by plastic materials may induce both a weakening of flavour and changes to the organic profile of packaged food products. This has mainly been reported for aqueous food, such as fruit juices, or model solutions, where the partition coefficient of aromas between food and packaging strongly favours sorption into the plastic material (Kwapong \& Hotchkiss 1987, Sizer et al. 1988). However, there are many discrepancies in reported partition coefficient values (Kutty et al. 1994, Hernandez-Munoz et al. 2001, Tehrany \& Desobry 2004). The possible reasons include: i) sorption kinetic studies performed without reaching the thermodynamic equilibrium (Gavara et al. 1996, Lebossé et al. 1997, Feigenbaum et al. 1998), ii) aroma used beyond their concentrations limits, which yield to deviations from Henry sorption equilibrium. Besides, partitioning results obtained with model solutions are difficult to extrapolate to the behaviour of aroma compounds in real foods, which are generally multi-constituent and possibly multi-phase. Recent papers have shown that in complex solutions simulating food matrices, the partition coefficients between aroma compounds and polymers depend also on the interactions with macromolecules (lipids, polyoligosides or proteins). In particular, lipids compete with polymers concerning the transfer of aroma compounds into polyolefins (Van Willige et al. 2000a,b). Moreover, during long periods of storage of up to a year, changes in aroma composition were detected in the food matrix without any contact with the polymer (Ducruet et al. 2001, Berlinet et al. 2005). In this case it is important to understand how the reactivity of the aroma compound in the matrix can influence the absorption of the aroma compounds by the packaging material.

Although PET and PVC are known to be good barriers to oxygen, in comparison with polyolefins, PET (one of the most common packaging polymers) and PVC (which is not widely used to package flavoured drinks), have seldom been tested (Ducruet et al. 2001, Van Willige et 
al. 2002a, Berlinet et al. 2005) for their barrier properties to aroma. The objective of the present study was to provide additional results on the sorption of aroma compounds in glassy polymers such as PET and PVC during long storage periods and to compare the kinetic sorption process with the degradation process, which also can reduce the amount of aroma. To make the results valuable for industry, the sorption and degradation kinetics were assessed on real food products and real packaging materials. Since the thermodynamic equilibrium cannot be obtained when the rate constants of both processes have similar orders of magnitude, the apparent partition coefficients were derived from an approach based on a new approximated solution proposed by Vitrac and Hayert (2006) to identify transport properties (including the partition coefficient) from censored kinetics (i.e. without reaching the thermodynamic equilibrium).

\section{Materials and methods}

\section{Packaging materials}

All the bottles were supplied from Teisseire S.A France. Strawberry syrups were packaged in rigid PVC bottles (PVC1, PVC2: average thickness: $1 \mathrm{~mm}$ ) and in amorphous PET bottles (PET1 and PET2; average thickness: $0.75 \mathrm{~mm}$ ). PVC1 was made using GFG 52 D resin from Dorlyl; it is suitable for contact with oils and is stabilized with an organotin stabilizer. PVC2 was manufactured by Teisseire. PET1 was manufactured from Ramapet, and PET2 from Shinpet. The surface area / volume in $\mathrm{dm}^{2} \mathrm{l}^{-1}$ ratio was approximately $=6$. Packaging in glass bottles (GL) was used as a reference to test the stability of the syrup without the influence of polymer contact.

\section{Strawberry syrup}

Strawberry syrup was obtained by mixing a sucrose syrup $\left({ }^{\circ}\right.$ Brix: $\left.64.5+/-1\right)$ and fruit juices (strawberry, elder and lemon juices). Nature-identical flavouring substances were also included. The $\mathrm{pH}$ of the strawberry syrup was $2.65+/-0.2$ and its shelf life was 18 months. 
After flash-pasteurisation at $105^{\circ} \mathrm{C}$ for $30 \mathrm{sec}$, syrup samples were packaged at ambient temperature under aseptic conditions. All bottles (PET, PVC and glass) were sealed after filling with aluminium foil in order to avoid a cap effect. The packaged syrups were stored at $20^{\circ} \mathrm{C}$

\section{Solvent extraction of the syrup}

$200 \mathrm{ml}$ of syrup, $200 \mathrm{ml}$ of Milli Q water and $500 \mu \mathrm{l}$ of tridecane solution (used as an internal standard, $500 \mu \mathrm{l}^{-1}$ ) were mixed in a 1 litre flask. Volatile compounds in the strawberry syrup were extracted three times using distilled dichloromethane, with 80,30 and $30 \mathrm{ml}$ for $30 \mathrm{~min}, 15$ min and $15 \mathrm{~min}$ respectively, at $0^{\circ} \mathrm{C}$ while stirring. Organic phases were separated from the aqueous phase and pooled. The dichloromethane extracts were dried over anhydrous $\mathrm{Na}_{2} \mathrm{SO}_{4}$ and concentrated using a Kuderna- Danish column. Analysis were done in triplicate.

\section{Solvent extraction of polymers}

At the end of each period of contact, the strawberry syrup and its packaging were separated. The plastic bottle (PET or PVC) was carefully and rapidly rinsed twice with ultra pure water, then with ethanol, and finally wiped before cutting. Because of the heterogeneous thickness of bottles, samples were taken by cutting pieces from three sections of a bottle (top, bottom and middle) and then pooled. Approximately $7 \mathrm{~g}$ of each pooled sample was then plunged immediately into a 100 $\mathrm{ml}$ flask containing distilled diethyl ether $(95 \mathrm{ml}) .2 \mathrm{ml}$ of a solution of ethyl pentanoate in diethyl ether $\left(100 \mu \mathrm{ll}^{-1}\right)$ were added as an internal standard. The flasks were tightly plugged with Teflon caps and extraction was carried out for 2 hours at $15{ }^{\circ} \mathrm{C}$ with magnetic stirring. Solvent extracts were dried with sodium sulfate and filtered over glass wool. Diethyl ether extracts were concentrated using a Kuderna- Danish apparatus.

Two plastic bottles were analyzed for each contact period. The extraction process was repeated twice for each bottle so as to enable analysis in duplicate of the plastic material after each period of contact. 


\section{Mass spectra}

Identification of the constituents was achieved using gas chromatography-mass spectrometry (GCMS). The GC-MS system consists of a Fisons GC-8000 chromatograph and a MD 800 mass spectrometer (Fisons Instruments, Les Ulis, France). Separations were performed on a Supelcowax fused silica capillary column $(0.32 \mathrm{~mm}$ x $30 \mathrm{~m} ; 0.5 \mu \mathrm{m}$; Supelco, Bellefonte, PA). The linear flow velocity of helium was $32 \mathrm{~cm} \mathrm{sec}^{-1}$. The column was maintained at $30^{\circ} \mathrm{C}$ for 10 min and then programmed at $240^{\circ} \mathrm{C}$ for SPME analysis and $260^{\circ} \mathrm{C}$ for solvent extracts at $5^{\circ} \mathrm{C} \mathrm{min}^{-}$

${ }^{1}$. The split-splitless injector was at $230^{\circ} \mathrm{C}$. Solvent extracts were injected into the splitless/split system (the split valve was closed after $30 \mathrm{sec}$ ). Electron ionization mass spectra were recorded under the following conditions:

capillary direct interface, $250^{\circ} \mathrm{C}$; ion source, $200^{\circ} \mathrm{C}$; ionization voltage, $70 \mathrm{eV}$; mass range, $29-300$ $\mathrm{m} / \mathrm{z}$; electron multiplier voltage, $450 \mathrm{~V}$; scan rate $3 \mathrm{scans} \mathrm{sec}^{-1}$.

Mass spectral matches were made by comparison with NIST and INRAMASS mass spectra libraries. Kovat's Indices of authentic compounds compiled in the INRAMASS library were used to confirm identification.

\section{Estimation of apparent partition coefficients}

The partition coefficient is defined from the ratio of concentrations of aroma at thermodynamic equilibrium, noted $\left.C_{P}\right|_{e q}$ and $\left.C_{F}\right|_{e q}$ respectively in the packaging material $(\mathrm{P})$ and in Food $(\mathrm{F})$ :

$$
K=\frac{\left.C_{P}\right|_{e q}}{\left.C_{F}\right|_{e q}}
$$

It is emphasized that equation (1) is valid whatever the considered equilibrium. Since the equilibrium was not reachable due to insufficient contact time (even after one year) or due to aroma degradation during storage, the equilibrium was extrapolated from the kinetic phase diagram corresponding to the experimental sorption kinetic, which was recently proposed by 
Vitrac and Hayert (2006). Only the main features of KPD relevant for the current application are reported here. A kinetic phase diagram, noted KPD, consists in plotting the sorption mass flux or equivalently the variation of the residual concentration in $\mathrm{P}$ with time, $\frac{\left.d C_{P}\right|_{t}}{d t}$ versus the residual concentration in $\mathrm{P},\left.C_{P}\right|_{t}$. During a sorption experiment, the expected concentration in $\mathrm{P}$ at equilibrium corresponds in the KPD space $\left(\left.C_{P}\right|_{t},\left.\frac{d C_{P}}{d t}\right|_{\left.C_{P}\right|_{t}}\right)$ to the value $\left(\left.C_{P}\right|_{e q}, 0\right)$. The interesting feature of the KPD space for the interpretation of sorption kinetics governed by diffusion in $\mathrm{P}$ and diffusion-convection in $\mathrm{F}$ is that after an initial rapid non-linear decay of $\frac{\left.d C_{P}\right|_{t}}{d t}$ with $\left.C_{P}\right|_{t}$, the variation of $\frac{\left.d C_{P}\right|_{t}}{d t}$ is almost linear with $\left.C_{P}\right|_{t}$. As a result, it is possible in the KPD space to extrapolate linearly the theoretical equilibrium state. Besides, a possible competition between sorption in $\mathrm{P}$ and degradation in $\mathrm{F}$ is easily detected by a change in curvature of the KPD. Thus a change in the decay of the KPD slope $\frac{d}{\left.d C_{P}\right|_{t}}\left(\left.\frac{d C_{P}}{d t}\right|_{\left.C_{P}\right|_{t}}\right)$ is interpreted as a degradation process, which tends to dominate the sorption process.

In this work, $\left.C_{P}\right|_{e q}$ was linealy extrapolated from the last experimental point KPD, for which $\frac{d}{\left.d C_{P}\right|_{t}}\left(\left.\frac{d C_{P}}{d t}\right|_{\left.C_{P}\right|_{t}}\right)$ was monotonous (i.e. increasing or constant). The same process was applied for the concentration in the liquid. A key step in the KPD approach is calculation of the derivatives of the concentration with time when the experimental data are unevenly sampled and noisy. In this work, we use an efficient non deterministic filtering technique based on local polynomial approximants as detailed and discussed in Vitrac and Hayert (2006). By noting with a superscript "extrap" the extrapolated quantities, the apparent partition coefficient, $\mathrm{K}_{\mathrm{app}}$, corresponding to experimental data were calculated from: 
$K_{a p p}=\frac{\left.C_{P}\right|_{e q} ^{\text {extrap }}}{\left.C_{F}\right|_{e q} ^{\text {extrap }}}$

It is emphasized that $\mathrm{K}_{\mathrm{app}}$ may differ from the real $\mathrm{K}$ value, however it is the best estimator according to the data available and our knowledge of sorption mechanisms. Confidence intervals on $\mathrm{K}_{\mathrm{app}}$ were derived by Monte Carlo sampling consisting in adding a white noise similar to the experimental error (relative error of $15 \%$ ) to kinetic data and in repeating the whole analysis. Each confidence interval was based on the $2.5^{\text {th }}$ and $97.5^{\text {th }}$ percentiles of at least 200 Monte Carlo trials.

Statistical analysis

Sorption experiments were analyzed using a one-way ANOVA program. When the differences were significant $(p<0.05)$, Duncan's test was used to check the differences between pairs of groups and was carried out using XLSTAT-Pro 7.0 software (Addinsoft, Paris, France).

\section{Results and discussion}

Sorption of the aroma compounds into PET and PVC

In order to monitor the sorption of aroma compounds, the strawberry syrup and the plastic material were extracted and analysed at different time points during the 330-day storage period. In the case of PVC, the presence in solvent extracts of additives and small oligomers along with absorbed volatile compounds produced more complex GC profiles than those seen with PET. Some of these additives were tentatively identified in the extracts of the syrup. (Table 1).

[Insert Table 1 here]

These compounds originate from the degradation of additives for example plasticizer, lubricants or modifiers (Gachter and Muller, 1990). Some can migrate into the syrup such as benzaldehyde, 
acetophenone and 2-ethylhexanol. By solvent extraction of the syrup or the packaging, these additives were extracted and co-eluted with the aroma compounds by GC. Thus, of the 38 aroma compounds previously identified in the syrup at the initial time of storage (Ducruet et al. 2001), only 14 compounds can be quantified in both kinds of packaging and in the syrup over the 330day storage period (Table 2).

\section{[Insert Table 2 here]}

The final concentration of the aroma compounds into the syrups stored in both PET and PVC bottles were compared to their initial concentrations (Figure 1). During shelf life, aroma compounds decreased by hydrolysis irrespective of the polymer. The decrease was more for short chain esters, and in particular for acetic acid esters and ethyl hexanoate (Figure 1A) compared to more stable compounds (Figure 1B). This reactivity is not related to the contact with polymer as it was previously found to occur during the storage of the syrup in a glass bottle (Ducruet et al, 2001).

[Insert Figure 1 here]

The greater reactivity was observed for short chain esters (methyl or ethyl esters) and acetic acid esters and can be explained by the low steric hindrance around their carbonyl group in contrast to linear longer chain esters (butyl, hexyl or octyl esters) and specially to branched esters (ethyl 2methylbutanoate, ethyl 3-methylbutanoate and 3-methylbutyl 3-methylbutanaote). These results demonstrated the instability of the aroma formulation for long periods of storage in acidic condition such as it was also found in the case of citrus flavoured drinks (Sizer et al. 1988, Berlinet et al. 2005)

The sorption of the aroma compounds from strawberry syrup into PET and PVC was monitored 
with time. The sorption of the 14 aroma compounds over 330 days of storage was compared to their initial concentration into the syrup (Table 2). The sorption into both kinds of packaging materials was found to be weak. The sorption was generally lower than $0.1 \%$ in all cases except for octyl butanoate which reached $0.15 \%$ in both PET samples, and $0.57 \%$ or $0.26 \%$ respectively in PVC1 and in PVC2 samples. After one year of storage into both samples of PET and PVC, if we consider the case of the octyl butanoate and hexyl acetate, as an example, their concentrations decreased by $30-43 \%$ and $67-81 \%$ respectively (Figure 1 ) although the sorption of these compounds into PET and PVC only represented $0.15-0.57 \%$ and $0.013-0.023 \%$ of the initial amount, respectively (table 1). These glassy materials showed their resistance to sorption by aroma and thus the main parameter which had an impact on the aroma formulation was the hydrolytic process into the syrup.

Few papers reported quantitative measurement of the sorption of aroma compounds into PET for real foods over a long time storage especially for thick materials such as bottles. For soft drinks flavoured with orange oil and stored in PET during 12 weeks, Nielsen (1994) showed that only 2.1 $\%$ and $1.4 \%$ of the initial concentrations of myrcene and of limonene were respectively sorbed by the polymer. Berlinet et al. (2005) compared the initial amounts of these two aroma compounds in orange juice and the quantities adsorbed in PET after 5 months of storage. They found an adsorption of between 0.2 and $0.3 \%$ of the initial levels present. These data were in line with the findings of Van Willige et al. (2003) who stated that only three flavour compounds (limonene, $\beta$ myrcene and decanal) were absorbed by PET. The percentage absorption of PET from juice containing limonene, $\beta$-myrcene, and decanal reached only $0.1 \%, 0.1 \%$ and $2.8 \%$ respectively, after one month of storage. When orange juice was stored in PET, the sorption of these two compounds was lower. The constituents of the juice (pulp, pectin), missing in the soft drink, may play a competitive role against the sorption into PET. The difference in the behaviour of the aroma compounds whether they are present in a simple solution or a more complex food was noticed by Leufven \& Hermansson (1994). The sorption of aroma compounds into PET was lower when 
[Insert Figure 2 here]

In both PVC and particularly PVC1, the sorption of most aroma compounds increased with the square root of time, following a Fickian mode, as we were able to show for more stable compounds such as 3-methylbutyl-3-methylbutanoate. Their sorption kinetics and their interpretation as kinetic phase diagrams are shown in figure 2. Open symbols plot experimental values as measured (duplicate experiments) whereas filled symbols plot non-deterministically filtered data as described by Vitrac and Hayert (2006) (figures 2 A-D). The continuous lines depict a cubic spline model, whose values and first derivatives fit the filtered ones. Versus the square root of time, the kinetics show a subsequent delay related to a possible external mass transfer resistance, a linear segment followed by a part with a decreasing slope. The presence of a linear segment confirmed that the sorption was controlled by the diffusion. The following sharp change in slope with a possible negative slope is related to a dynamic modification of sorption conditions. 
This modification was created by the degradation of the aroma compound in the liquid phase, which modified in return the attainable equilibrium state. The expected equilibrium concentration in the packaging material was consequently decreasing.

These trends were more discernible in the kinetic phase diagram (KPD), which plots the first derivative of the concentration in the packaging material with time versus its primitive (i.e. the concentration itself) (figures $2 \mathrm{E}$ and $2 \mathrm{~F}$ ). Filled and open symbols plot respectively the filtered values and the $95 \%$ confidence interval as assessed by Monte Carlo sampling. A non-diffusive behaviour such as the one related to a reaction in the liquid phase is associated to a change in convexity in the diagram. Indeed, a convex shape of the KPD or a sharp decrease of the absorbed mass flux when the absorbed amount increase cannot be related anymore to diffusion (see Vitrac and Hayert, 2006 for further details). This rule could not however be applied to the earlier stage of desorption kinetics since the mass flux was not estimated with enough accuracy. The KPD were used to predict the equilibrium, which would be reached if the sorption conditions as assessed during the linear part of the concentration versus the square root of times were prolonged, since in the parabolic regime of diffusion, the KPD is linear. The concentrations at equilibrium were linearly extrapolated from the convex part of the KPD to the horizontal line $\left.d C_{P}\right|_{t} / d t=0$. The linear extrapolation inferred from the confidence envelope of the KPD appears as dashed lines.

\section{Affinity of aroma compounds for PVC and PET}

Apparent partition coefficients $K_{a p p}$ derived from the extrapolation of concentrations expected at equilibrium in absence of reaction are plotted versus $\log \mathrm{P}$ (octanol-water partition coefficient) (figures 3A and 3B) and versus the molecular weight (figures 3C and 3D) for PET (figures 3A and 3C) and for PVS (figures 3B and 3D).

[Insert Figures 3 A, B, C, D here] 
It is highlighted that for the set of tested aroma compounds, $\log \mathrm{P}$ and molecular weight are not independent quantities. $\log \left(\mathrm{K}_{\mathrm{app}}\right)$ appeared almost linearly correlated to log $\mathrm{P}$ values. Whatever the polymer, sorption was selective and increased with the chain length of the linear butanoic acid esters (butyl butanoate, hexyl butanoate and octyl butanoate), a behaviour quite similar to that reported by Shimoda et al. (1987) with respect to polyethylene. However the correlation was poorer with the molecular mass than with the $\log \mathrm{P}$, due to branching into the molecules. Branching or unsaturation in the backbone of the molecule (for an equal carbon number) caused sorption to decrease, as can be seen for 3-methylbutyl-3-methylbutanoate by comparison with hexyl butanoate in PET (Figure 3C).

Quite similar partition coefficients were obtained for both PET (PET1 and PET2) and both PVC (PVC1 and PV2). Both PET samples sorbed the esters to a lesser extent, PVC1 displayed the highest level of sorption, three to ten-fold more than both samples of PET mainly for octyl butanoate and 3-methylbutyl- 3-methylbutanoate Few studies have dealt with the sorption of aroma compounds into PVC. Koszinowski \& Piringer (1987), and DeLassus (1994) showed that diffusion coefficients in PVC were several orders of magnitude lower than in polyethylene and polypropylene. In contrast, their solubilities (S) were about one order of magnitude lower in polyolefins. Barrier behaviour evaluated by the permeability coefficient $\mathrm{P}(\mathrm{P}=\mathrm{DxS})$, resulting from the kinetic effect (coefficient of diffusion, D), and the thermodynamic effect (S), only gave a small advantage for PVC over polyolefins.

With PET, the coefficients of diffusion and solubility of the volatile compounds are lower (Pennarun et al. 2004) than those measured for polyolefins, so a low interaction can be observed with this polymer. Figure $3 \mathrm{C}$ and $3 \mathrm{D}$ shows that both PET samples were more or less equivalent and were less sorbent than PVC 2, except for cyclic esters such as ethyl cinnamate and ethyl salicylate The sorption of these compounds in PET reached the level of sorption observed in PVC2. These compounds exhibited a differential affinity for PET, probably because of the 
similarity of their cyclic structure. This affinity could affect the typical flavour of the syrup related to the "wild strawberry note" which is associated with ethyl cinnamate, ethyl salicylate and ethyl benzoate.

In conclusion, the variation of $\mathrm{K}_{\mathrm{app}}$ values in PET was mainly correlated to the polarity of tested compounds as assessed by their $\log \mathrm{P}$ values. By contrast, the variations in $\mathrm{K}_{\text {app }}$ values for PVC were mainly related to their chain lengths

\section{Kinetics of sorption into PET and PVC for the unstable compounds}

The sorption kinetics of some compounds, (ethyl butanoate, hexyl acetate), showed the same typical trends in both types of PET (Figure 4).

\section{[Insert Figure 4 here]}

Sorption increased to a peak at 90 days and then declined until 150 days, reaching a state of equilibrium until 330 days.

Several hypotheses can be proposed to explain this behaviour.

1. Durning \& Russel (1985) proposed a model of diffusion with induced crystallization to describe the sorption kinetics of organic liquids which might trigger PET crystallization. Berlinet et al., (2005) showed that the absorption of aroma compounds (even at low levels) may be responsible for increasing the crystallinity of PET, over 6 months of storage. This "solvent induced crystallization" which was described in PET in contact with ethyl acetate by Hao et al. (1999), could lead to a structure modification of PET during 3 months of storage and then induce the release of the aroma compounds from the packaging. However this behaviour would have been observed for all the compounds specially those which are more sorbed such as octyl butanaoate, but it is not the case and this behaviour was only noticed for the more reactive compounds.

2. The sorption behaviour into PET of the more reactive aroma compounds could be explained in 
the following manner: during the first stage between 0 to 90 days, these compounds were slowly sorbed by PET, and hydrolysis into alcohols and acids started in the syrup. During the second period ( $90<\mathrm{t}<150$ days), degradation was the leading parameter, which resulted in desorption of the volatiles from PET, reaching an equilibrium between both phases (syrup and polymer). No alcohol or acid from the corresponding esters was identified in the PET extract. After 150 days, the equilibrium of aroma compounds between packaging and syrup was reached, taking account of degradation into the syrup. Thus, after 90 days, PET could play a positive role as a reserve for some of these unstable compounds.

As previously described (Ducruet et al 2001), esterified aroma compounds were hydrolysed in glass bottles and this was not influenced by polymer contact. The hydrolysis rate of volatile compounds displayed a first order kinetic. Stronger reactivity was observed for methyl or ethyl esters of acetic acid when compared with longer linear chain esters and particularly branched esters. These compounds were rapidly hydrolysed in the syrup packaged in glass bottles during the first 150 days. Same reactivity was observed in both kinds of polymers. As oxygen transfer through amorphous PET and rigid PVC were of the same order of magnitude, respectively $4.410^{-}$ ${ }^{11} \mathrm{~cm}^{2} \mathrm{sec}^{-1} \mathrm{~Pa}^{-1}$ and $3.410^{-11} \mathrm{~cm}^{2} \mathrm{sec}^{-1} \mathrm{~Pa}^{-1}$ (Branrup et al. 1989), the oxidation of these compounds cannot explain the observed difference between PET and PVC.

In the case of orange juice in contact with PET, recent results had already shown that, degradation due to the acid catalysis of aroma compounds ( $\alpha$-pinene, limonene, linalool) is the principal parameter controlling exchanges with the glassy material (Berlinet et al. 2005) and therefore the aromatic evolution of orange juice was not controlled by the packaging material but by reactions within the matrix itself. Polyolefins (polyethylene and polypropylene (in contact with a model medium containing highly reactive compounds such as limonene or pinene under acidic conditions may play a positive role in stabilising aroma compounds (Lebossé et al. 1997, Feigenbaum et al 1998, Reynier et al. 2004). Because the degradation process in the model system is of the same 
order of magnitude as diffusion into the polymers, the two phenomena are in competition. In the case of PET, transfer is very slow, and many studies, which considered contact times of insufficient duration, were not able to demonstrate this effect. In the case of contact between real food products during their shelf life (up to one year) and unstable aroma compounds such as short chain esters, the degradation of aroma compounds is more rapid than diffusion into PET. Release is less rapid than with polyolefins, and some stabilization effects of PET may be observed after only 150 days of storage, in line with the type trend of sorption kinetics.

In the context of food packaging interactions, the thermodynamic equilibrium of each aroma compound is expressed as the partition coefficient. Because the experimental determination of this partition coefficient may be prohibitive (Tehrany \& Desobry 2004), modelling has been proposed as an alternative (Dekker et al. 2003, Tehrany \& Desobry 2005). Models are available for polyolefins but extensions to glassy polymers such as PET or PVC are still pending. The main limitations consist in the availability of reference data, which are not subjected to bias due to a competition between slow sorption kinetics (longer than 150 days) and a fast degradation process. The production of apparent partition coefficient with minimum bias as assessed in this study using a kinetic phase diagram could be an alternative to the lack of published data. From the technological point of view, the loss of aroma for a particular food in contact with a glassy material must be envisaged as a consequence of both the sorption and degradation process. In the present case, the degradation of the aroma formulation of the syrup is mainly due to hydrolysis of esters.

\section{Conclusion}

This study shows that the interactions between aroma compounds and packaging may result in a dynamic and time-dependent change in food quality during shelf life. Two combined mechanisms contribute to a loss of aroma during long-term storage: the degradation process in the food product itself and the sorption process in the packaging material. Both effects were particularly noticeable 


\section{Acknowledgement}

This work was supported by the Société TEISSEIRE. The authors would like to thank Mr. ROUGE and Mrs RAYNAL for their efficient partnership during study-time.

\section{References}

Berlinet C, Ducruet V, Brillouet JM, Reynes M, Brat P. 2005. Evolution of aroma compounds in orange juice stored in PET. Food Additives and Contaminants 22:185-195

Brandrup J, Immergut EH, Grulke A. 1989. Polymer handbook, 443

Dekker M, Van Willige RWG, Linssen JPH, Voragen AGJ. 2003. Modelling the effect of oil/fat content in food systems on flavour absorption by LLDPE. Food Additives and Contaminants 20: $180-185$. 
DeLassus PT. 1994. Sorption and diffusion of flavors in plastic packaging. Flavor-food interactions, Mc Gorrin R. J., Leland J. V.; Eds.; ACS Symposium Series: Washington D. C., , pp152-161

Ducruet V, Fournier N, Saillard P, Feigenbaum A, Guichard E. 2001. Influence of packaging on the aroma stability of strawberry syrup during shelf life. Journal of Agricultural and Food Chemistry 49:2290-2297.

Durning CJ, Russel WB. 1985. A mathematical model for diffusion with induced crystallization (2), Polymer, 26:131-140.

Feigenbaum A, Lebossé R, Ducruet V. 1998. Polypropylene as active packaging material for aroma sorption from model orange juice. In: Food Flavors: Formation, Analysis, and Packaging Influences, Series: Developments in Food Science; Contis E. T., Ho C. T., Mussinan C. J., Parliment T. H., Shahidi F., Spanier A. M., Eds.; Elsevier, Netherlands, pp 743-751.

Gächter R, Muller H. 1990. Plastics additives handbook., $3^{\text {rd }}$ Edition, Hanser, Munich. p10

Gavara R, Hernandez RJ, Giacin J. 1996. Methods to determine partition coefficient of organic compounds in water/polystyrene systems. Journal of Food Science 61: 947-952.

Hao OY, Shore SH. 1999. Ethyl acetate transport in poly(ethylene terephthalate). Journal of Applied Physics 85:1148-1152

Hernandez-Munoz P, Catala R, Gavara R 2001. Food aroma partition between packaging materials and fatty food simulants. Food Additives and Contaminants, 18: 673-682

Kutty V, Braddock RJ, Sadler GD. 1994. Oxidation of D-limonene in presence of low-density polyethylene. Journal of Food Science 59:402-405.

Kwapong OY, Hotchkiss JH. 1987. Comparative sorption of aroma compounds by polyethylene and ionomer food-contact plastics. Journal of Food Science 52:761-764.

Lebossé R, Ducruet V, Feigenbaum A. 1997. Interactions between reactive aroma compounds from model citrus juice with polypropylene packaging film. Journal of Agricultural and Food 
Chemistry 45:2836-2842.

Leufvén A, Hermansson C. 1994. The sorption of aroma components from tomato juice by foodcontact polymers. Journal of the Science of Food and Agriculture 64:101-105

Nawar WW, 1971. Some variables affecting composition of headspace aroma. Journal of Agricultural and Food Chemistry 19:1057-1059.

Nielsen TJ, 1994. Limonene and Myrcene sorption into refillable polyethylene terephtalate bottles, and washing effects on removal of sorbed compounds. Journal of Food Science 59:227-230.

Roberts DD, Elmore JS, Langley KR, Bakker J. 1996. Effects of sucrose, guar gum, and carboxymethylcellulose on the release of volatile flavor compounds under dynamic conditions. Journal of Agricultural and Food Chemistry 44:1321-1326

Shimoda M, Matsui T, Osajima Y. 1987. Effect of number carbon atoms of flavor compounds on diffusion, permeation and sorption with polyethylene. Nippon shokuhin kogyo gakkaiski, 34: 535539

Sizer CE, Waugh PL, Edstam S, Ackermann P. 1988. Maintaining flavor and nutrient quality of aseptic orange juice. Food Technolology 42:152-159

Koszinowski J, Piringer O. 1987. Food Package compatibility and migration. Journal of Plastic Film Sheeting 3:96-111

Nahon DF, Navarro y Koren PA, Roozen JP, Posthumus MA. 1998. Flavor Release from Mixtures of Sodium Cyclamate, Sucrose, and an Orange Aroma. Journal of Agricultural and Food Chemistry 46:4963-4968

Nielsen TJ, Jägerstad M, Öste R E, Wesslén BO. 1992. Comparative absorption of low molecular aroma compounds into commonly used food packaging polymer films. Journal of Food Science $57: 490-492$

Nielsen TJ. 1994. Limonene and Myrcene sorption into refillable polyethylene terephtalate bottles, and washing effects on removal of sorbed compounds. Journal of Food Science 59:227-230.

Pennarun PY, Dole P, Feigenbaum A. 2004. Functional barriers in PET recycled bottles. Part I. 
Determination of diffusion coefficients in bioriented PET with and without contact with food simulants. Journal of Applied Polymer Science 92:2845-2858

Reynier A, Dole P, Fricoteaux F, Saillard P., Feigenbaum A.2004. Stabilization of aroma compounds through sorption-release by packaging polymers. Journal of Agricultural and Food Chemistry 52:5653-5662

Tehrany EA, Desobry S. 2004. Partition coefficients in food packaging systems : a review. Food Additives and Contaminants 21:1186-1202

Tehrany EA, Desobry S. 2005. Comparison between the different calculation methods of partition coefficient of aroma compounds with a difference chemical classes in octano/water system; Sciences des Aliments, 25:23-36

Van Willige RWG, Linssen JPH, Voragen AGJ. 2000a. Influence of food matrix on absorption of flavour compounds by linear low-density polyethylene: proteins and carbohydrates. Journal of the Science of Food and Agriculture 80: 1779-1789.

Van Willige RWG, Linssen JPH, Voragen AGJ. 2000b. Influence of food matrix on absorption of flavour compounds by linear low-density polyethylene: oil and real food products. Journal of the Science of Food and Agriculture 80: 1790-1797

Van Willige RW, Linssen JPH, Meinders MBJ, Van der Stege H J, Voragen AGJ. 2002. Influence of flavour absorption on oxygen permeation through LDPE, PP, PC and PET plastics food packaging. Food additives and contaminants 19:303-313

Van Willige RWG, Linssen JPH, Legger-Huysman A, Voragen AGJ. 2003. Influence of flavour absorption by food-packaging materials (low-density polyethylene, polycarbonate and polyethylene terephtalate) on taste perception of a model solution and orange juice. Food additives and contaminants 20:84-91.

Vitrac O, Hayert M. 2006. Identification of diffusion transport properties from desorption/sorption 
kinetics: an analysis based on a new approximation of Fick equation during solid-liquid contact.

Industrial Engineering Chemical Research, 45:7941-7956. 
Table 1 Extraneous compounds tentatively identified in the syrup or in the packaging material extracts during storage

\begin{tabular}{|c|c|c|c|}
\hline Packaging & $\begin{array}{c}\text { Compounds } \\
\text { initially present in the } \\
\text { polymer }\end{array}$ & $\begin{array}{l}\text { Migration into the } \\
\text { syrup }\end{array}$ & Origin of compounds $*$ \\
\hline PVC & $\begin{array}{l}\text { 2-ethylhexanol } \\
\text { 2-ethylhexanol acetate } \\
\text { benzaldehyde } \\
\text { styrene } \\
\text { isooctyl thioglycolate } \\
\text { acetophenone }\end{array}$ & $\begin{array}{l}\text { Yes after } 250 \text { days } \\
\text { No } \\
\text { Yes } \\
\text { No } \\
\\
\text { Yes }\end{array}$ & $\begin{array}{l}\text { thermal degradation of plasticizer } \\
\text { ABS or MBS impact modifier } \\
\text { derived from an organotin stabilizer }\end{array}$ \\
\hline PET & $\begin{array}{l}\text { 2-ethylhexanol } \\
\text { benzaldehyde } \\
\text { naphtlalene, } \\
\text { linear aldehydes } \\
\\
\text { acetophenone }\end{array}$ & $\begin{array}{l}\text { Yes before } 225 \text { days } \\
\text { Yes } \\
\text { No. } \\
\text { No } \\
\\
\text { Yes }\end{array}$ & $\begin{array}{l}\text { thermal degradation of plasticizer } \\
\text { possible degradation products of the } \\
\text { polyethylene waxes used as lubricants in } \\
\text { PET }\end{array}$ \\
\hline
\end{tabular}

*Gachter \& Muller, 1990 
Table 2 : Amount of aroma compounds sorbed into PET and PVC after 90 days* ${ }^{*}$ and 330 days of storage at $20^{\circ} \mathrm{C}$. Means of two determinations

\begin{tabular}{|c|c|c|c|c|c|c|c|c|c|c|}
\hline Volatile Compound & Code & $\begin{array}{r}\mathrm{Co}^{*} \\
\mathrm{mg} \mathrm{l}^{-1}\end{array}$ & $\begin{array}{c}\text { PET1 } \\
\mu \mathrm{g} / 6 \mathrm{dm}^{2}\end{array}$ & $\begin{array}{c}\% \\
\text { sorption }\end{array}$ & $\begin{array}{c}\text { PET2 } \\
\mu \mathrm{g} / 6 \mathrm{dm}^{2}\end{array}$ & $\begin{array}{c}\% \\
\text { sorption }\end{array}$ & $\begin{array}{c}\text { PVC1 } \\
330 \text { days } \\
\mu \mathrm{g} / 6 \mathrm{dm}^{2}\end{array}$ & $\begin{array}{c}\% \\
\text { sorption }\end{array}$ & $\begin{array}{c}\text { PVC2 } \\
330 \text { days } \\
\mu \mathrm{g} / 6 \mathrm{dm}^{2}\end{array}$ & $\begin{array}{c}\% \\
\text { sorption }\end{array}$ \\
\hline Butyl butanoate & BB & 24.6 & 3.7 & $0.015 \mathrm{c}$ & 3.8 & $0.015 \mathrm{c}$ & 7.8 & $0.032 \mathrm{a}$ & 4.9 & $0.020 \mathrm{~b}$ \\
\hline Hexyl butanoate & $\mathrm{BH}$ & 9.6 & 2.3 & $0.024 \mathrm{c}$ & 2.6 & $0.027 \mathrm{c}$ & 11 & $0.115 \mathrm{a}$ & 5.1 & $0.053 \mathrm{~b}$ \\
\hline Octyl butanoate & $\mathrm{BO}$ & 8.4 & 13.1 & $0.156 \mathrm{c}$ & 12.8 & $0.150 \mathrm{c}$ & 47.8 & $0.569 \mathrm{a}$ & 22.1 & $0.263 \mathrm{~b}$ \\
\hline Ethyl hexanoate & $\mathrm{HE}$ & 167.5 & $24.5^{* *}$ & $0.015 \mathrm{c}$ & $27.8^{* *}$ & $0.017 \mathrm{~b}$ & 54.3 & $0.032 \mathrm{a}$ & 29.1 & $0.017 \mathrm{~b}$ \\
\hline $\begin{array}{l}\text { 3-Methylbutyl 3- } \\
\text { methylbutanoate }\end{array}$ & 3MB3MB & 134.5 & 12 & $0.009 \mathrm{c}$ & 16.8 & $0.012 \mathrm{c}$ & 146.9 & $0.109 \mathrm{a}$ & 62.7 & $0.047 \mathrm{~b}$ \\
\hline $\begin{array}{l}\text { Ethyl 2- } \\
\text { methylbutanoate }\end{array}$ & $2 \mathrm{MBE}$ & 257.5 & 8.8 & $0.003 \mathrm{c}$ & 8.1 & $0.003 \mathrm{c}$ & 23.2 & $0.009 \mathrm{a}$ & 16.4 & $0.006 \mathrm{~b}$ \\
\hline $\begin{array}{l}\text { Ethyl 3- } \\
\text { methylbutanoate }\end{array}$ & $3 \mathrm{MBE}$ & 166.8 & 7.3 & $0.004 \mathrm{a}$ & 7.3 & $0.004 \mathrm{a}$ & 12.4 & $0.007 \mathrm{a}$ & 8.6 & $0.005 \mathrm{a}$ \\
\hline Hexyl acetate & $\mathrm{AcH}$ & 152.5 & $23^{* *}$ & $0.015 \mathrm{~b}$ & $25.8^{* *}$ & $0.017 \mathrm{~b}$ & 34.6 & $0.023 \mathrm{a}$ & 19.4 & $0.013 \mathrm{c}$ \\
\hline 3(Z)-Hexenyl acetate & $\mathrm{Ac} 3 \mathrm{H}$ & 142.2 & $11.4^{* *}$ & $0.008 \mathrm{c}$ & $13^{*}$ & $0.009 \mathrm{~b}$ & 21.3 & $0.015 \mathrm{a}$ & 12.7 & $0.009 \mathrm{~b}$ \\
\hline Octyl acetate & $\mathrm{AcO}$ & 10.4 & $9.1^{* *}$ & $0.087 \mathrm{a}$ & $8.5^{* *}$ & $0.082 \mathrm{a}$ & 9.2 & $0.088 \mathrm{a}$ & 4.3 & $0.041 \mathrm{a}$ \\
\hline Methyl cinnamate & CIME2 & 530.5 & 149.5 & $0.028 \mathrm{~b}$ & 164.9 & $0.031 \mathrm{~b}$ & 283.5 & $0.053 \mathrm{a}$ & 149.7 & $0.028 \mathrm{~b}$ \\
\hline Ethyl salicylate & 2OHBzE & 120.4 & 45.5 & $0.038 \mathrm{~b}$ & 40.8 & $0.034 \mathrm{~b}$ & 85.7 & $0.071 \mathrm{a}$ & 42.9 & $0.036 \mathrm{~b}$ \\
\hline Ethyl benzoate & BzE & 47.5 & 7.2 & $0.015 \mathrm{bc}$ & 6.3 & $0.013 \mathrm{c}$ & 43 & $0.091 \mathrm{a}$ & 31.9 & $0.067 \mathrm{ab}$ \\
\hline$\gamma$-decalactone & GDL & 339.2 & 21 & $0.006 \mathrm{c}$ & 13.6 & $0.005 \mathrm{c}$ & 132.3 & $0.039 \mathrm{a}$ & 43.2 & $0.013 \mathrm{~b}$ \\
\hline
\end{tabular}

* : concentration of the aroma compounds into glass bottle at t0 day

Different letters in the \% sorption indicate significant differences at $p<0.05$ (Duncan) for each aroma compound between packaging materials. 

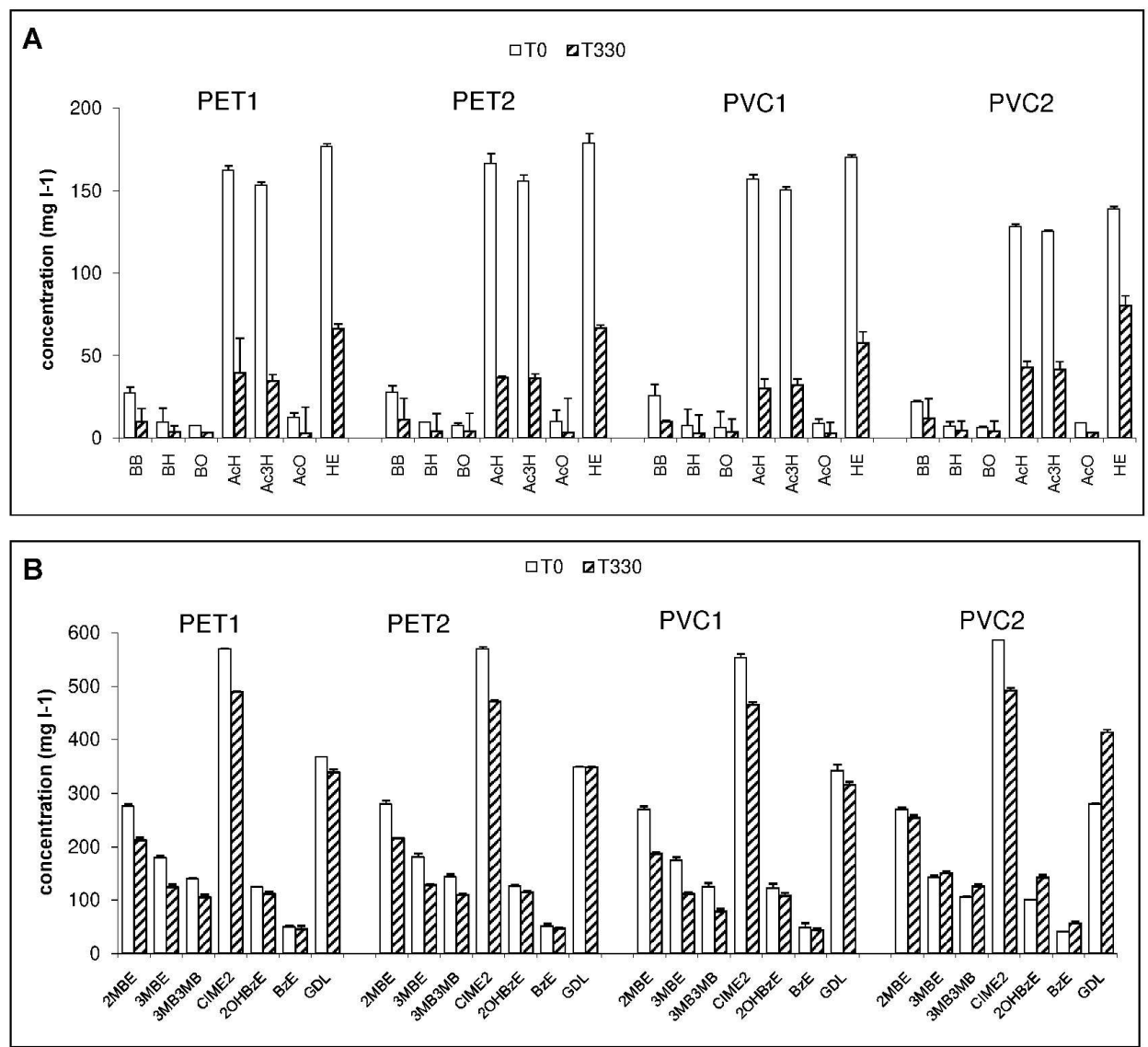

Figure 1 Concentration of the aroma compounds into the strawberry syrup at t 0 day and t330 days of storage into the 4 packaging materials $(n=3)$ $149 \times 141 \mathrm{~mm}(600 \times 600 \mathrm{DPI})$ 
Figure 2 A-D) Sorption kinetics of 3-methyl butyl 3-methyl butanoate in PET and PVC on a linear scale $(A, B)$ and versus the square root of time $(C, D)$. E-F) Kinetic phase diagram corresponding to figures $A$ and $B$ respectively. $1695 \times 1905 \mathrm{~mm}(72 \times 72 \mathrm{DPI})$ 

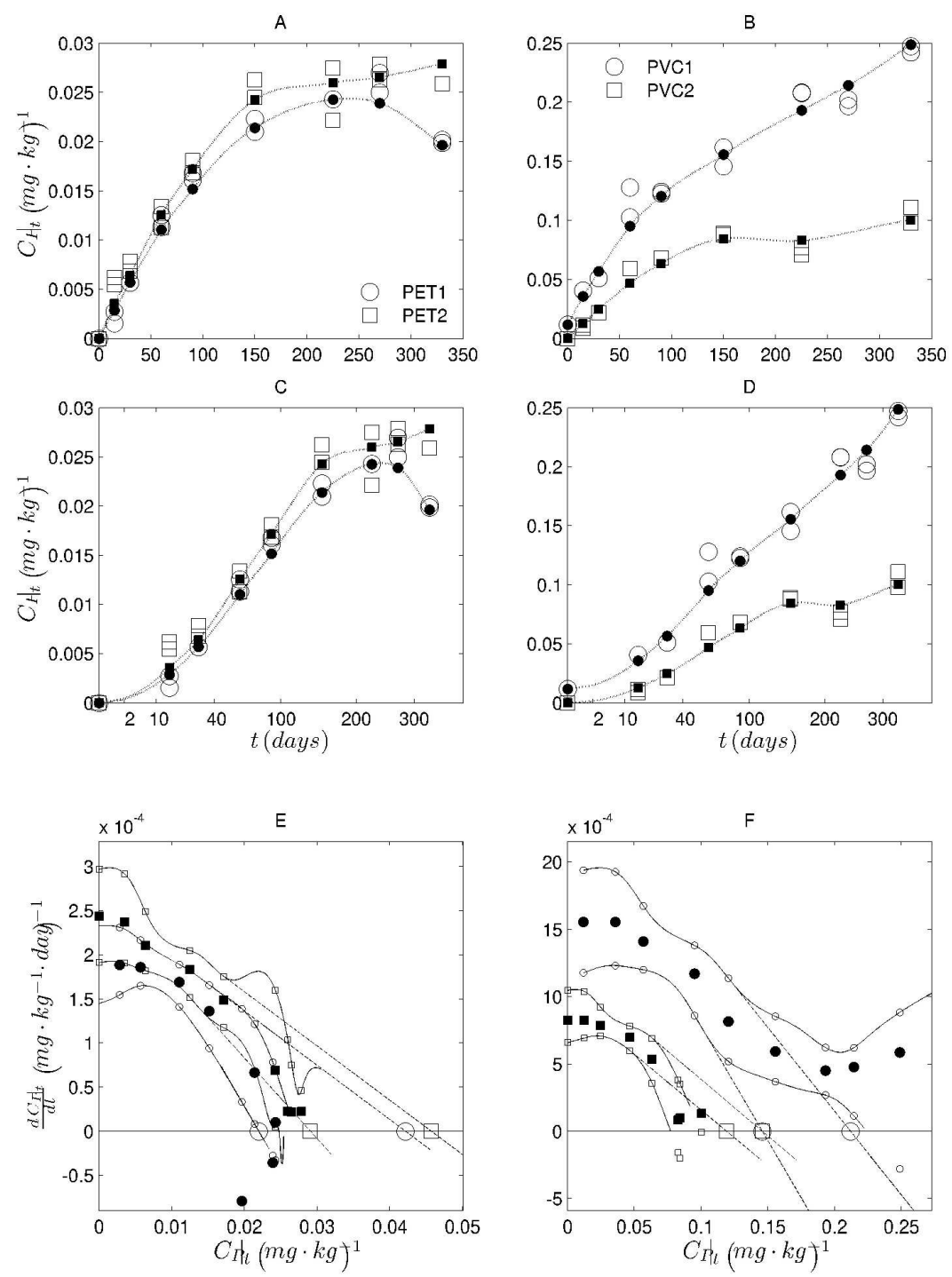

Figure 3 Apparent partition coefficients Kapp, in PET $(A, C)$ and PVC $(B, D)$ versus logP (octanol-water partition coefficient) $(A, B)$ and molecular weight $(C, D)$ of aroma compounds. Normal and italic fonts are used for PET1 and PVC1, and for PET2 and PVC2 respectively. The codes of aroma compounds are defined in Table 2. 

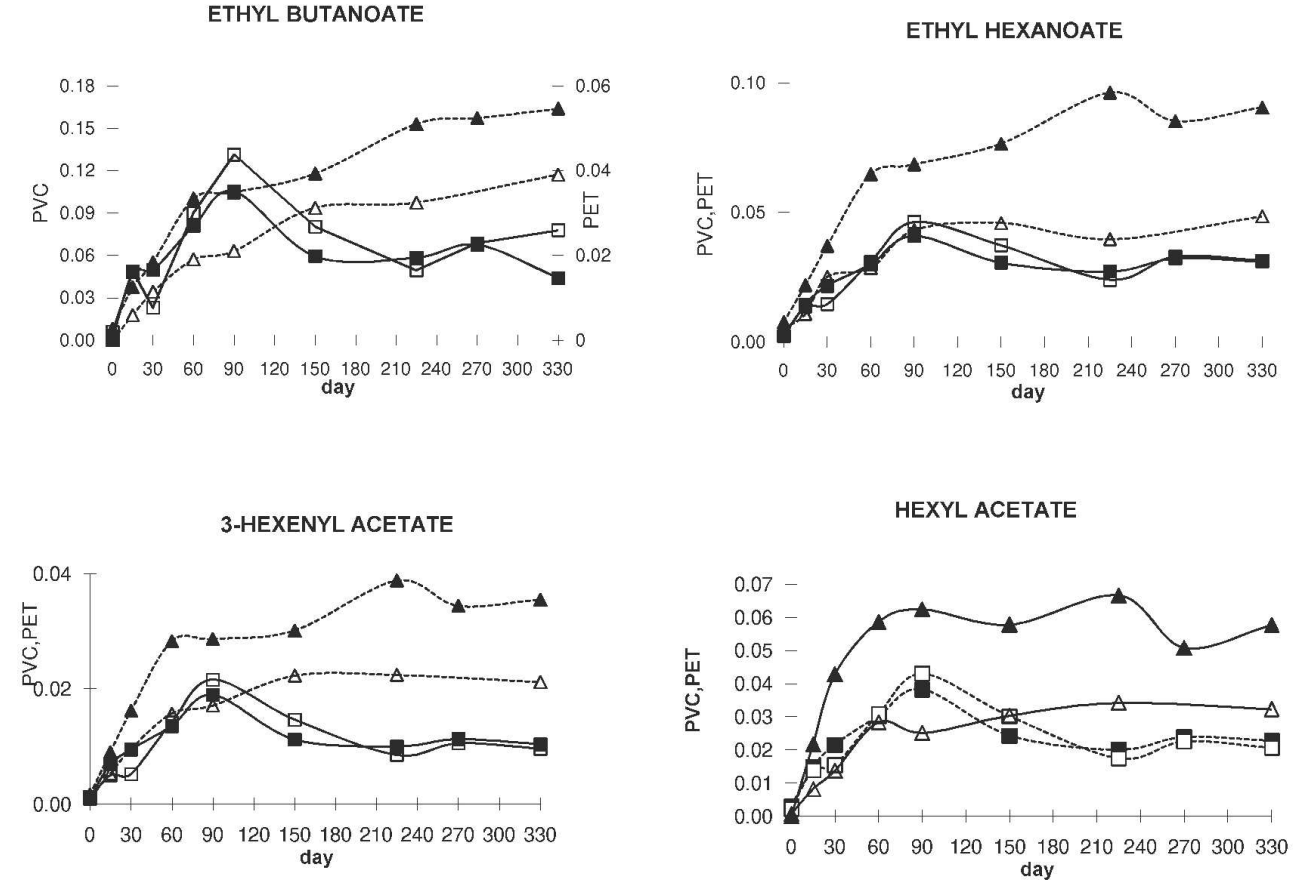

Figure 4 Sorption of aroma compounds ( $\mu \mathrm{g} / \mathrm{cm} 2$ ) into PET1( $)$, PET2 ( $\square) \operatorname{PVC1}(\mathbf{\Delta}) \operatorname{PVC2}(\Delta)$ versus time $145 \times 102 \mathrm{~mm}(600 \times 600 \mathrm{DPI})$ 